The FASEB Journal express article10.1096/fj.04-1913fje. Published online December 20, 2004.

\title{
Role for nitrosative stress in diabetic neuropathy: evidence from studies with a peroxynitrite decomposition catalyst
}

\author{
Irina G. Obrosova, ${ }^{, \dagger}{ }^{\dagger}$ Jon G. Mabley, ${ }^{\ddagger}$ Zsuzsanna Zsengellér, ${ }^{\ddagger}$ Tamara Charniauskaya,*
} Omorodola I. Abatan,* John T. Groves, ${ }^{\S}$ and Csaba Szabó ${ }^{\ddagger}$

*Department of Internal Medicine, University of Michigan, Ann Arbor, MI; ${ }^{\dagger}$ Pennington Biomedical Research Center, Louisiana State University System, Baton Rouge, LA; ${ }^{\mp}$ Inotek Pharmaceuticals Corporation, Beverly, MA; ${ }^{\S}$ Department of Chemistry, Princeton University, Princeton, NJ

Corresponding author: Irina G. Obrosova, Pennington Biomedical Research Center, Louisiana State University, 6400 Perkins Road, Baton Rouge, LA 70808. E-mail: obrosoig@pbrc.edu

\section{ABSTRACT}

Nitrosative stress, that is, enhanced peroxynitrite formation, has been documented in both experimental and clinical diabetic neuropathy (DN), but its pathogenetic role remains unexplored. This study evaluated the role for nitrosative stress in two animal models of type 1 diabetes: streptozotocin-diabetic mice and diabetic NOD mice. Control (C) and streptozotocindiabetic (D) mice were treated with and without the potent peroxynitrite decomposition catalyst FP15 (5 mg kg ${ }^{-1} \mathrm{~d}^{-1}$ ) for $1 \mathrm{wk}$ after 8 wk without treatment. Sciatic nerve nitrotyrosine (a marker of peroxynitrite-induced injury) and poly(ADP-ribose) immunoreactivities were present in $\mathrm{D}$ and absent in C and D+FP15. FP15 treatment corrected sciatic motor and hind-limb digital sensory nerve conduction deficits and sciatic nerve energy state in $\mathrm{D}$, without affecting those variables in C. Nerve glucose and sorbitol pathway intermediate concentrations were similarly elevated in D and D+FP15 vs C. In diabetic NOD mice, a 7-day treatment with either 1 or $3 \mathrm{mg} \mathrm{kg}^{-1} \mathrm{~d}^{-1}$ FP15 reversed increased tail-flick latency (a sign of reduced pain sensitivity); the effect of the higher dose was significant as early as 3 days after beginning of the treatment. In conclusion, nitrosative stress plays a major role in DN in, at least, type 1 diabetes. This provides the rationale for development of agents counteracting peroxynitrite formation and promoting peroxynitrite decomposition, and their evaluation in DN.

Key words: poly(ADP-ribose) polymerase $\cdot$ streptozotocin-diabetic rats $\cdot$ NOD mice $\bullet$ nerve conduction deficit • tail-flick latency

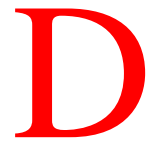
iabetic distal symmetric sensorimotor polyneuropathy affects up to $60-70 \%$ of patients with diabetes mellitus in the United States and is the leading cause of foot ulceration and amputation (1). The Diabetes Control and Complications Trial (DCCT) established the importance of hyperglycemia and other consequences of insulin deficiency in the pathogenesis of diabetic neuropathic changes culminating in peripheral nerve fiber damage and loss (2). Multiple mechanisms have been identified as secondary transducers of hyperglycemia in the pathogenesis of diabetic neuropathy, and among them increased aldose reductase activity (3-5), nonenzymatic 
glycation and glycooxidation (6), activation of protein kinase C (7), and impaired neurotrophic support $(8,9)$ are the best studied. All these mechanisms contribute to enhanced oxidative stress resulting from increased production of reactive oxygen species (ROS) and insufficient upregulation or down-regulation of antioxidative defense $(10)$. Growing evidence $(11,12)$ suggests that superoxide generated by both intramitochondrial (13) and extramitochondrial (14) sources is a primary free radical formed in hyperglycemic conditions, and a source of other highly reactive free radicals and oxidants, that is, hydroxyl radicals, hydrogen peroxide, and peroxynitrite, known to exert detrimental effects in tissue sites for diabetic complications (15).

Increased formation of the potent oxidant peroxynitrite (the product of superoxide anion radical reaction with nitric oxide) has recently been documented in both experimental $(11,12,16)$ and clinical diabetic neuropathy (17). Peroxynitrite causes nitration and nitrosylation, a condition called nitrosative stress, and reacts with a variety of biomolecules, including proteins, lipids, and DNA (18). DNA single-strand breakage in response to nitrosative stress has been implicated in poly(ADP-ribose) polymerase (PARP) activation (18-20). Nitrosative stress is also known to induce a variety of other downstream consequences in pathophysiological conditions associated with oxidative injury (21). However, the pathogenetic role of reactive nitrogen species in diabetic neuropathy remains unexplored. The present study was designed to evaluate the role for nitrosative stress in early diabetic neuropathy in two animal models of type 1 diabetes mellitusstreptozotocin-diabetic mice and diabetic NOD mice-using the potent peroxynitrite decomposition catalyst, Fe(III) tetrakis-2-(N-triethylene glycol monomethyl ether) pyridyl porphyrin (FP15) (18). Metalloporphyrins such as FP15 have been shown to rapidly rearrange peroxynitrite to nitrate in vitro (22-25) and in vivo (18), thus protecting biological targets from nitration $(26,27)$.

\section{MATERIALS AND METHODS}

The experiments were performed in accordance with regulations specified by the National Institutes of Health "Principles of Laboratory Animal Care, 1985 Revised Version" and University of Michigan and Inotek Pharmaceuticals Corporation Protocols for Animal Studies.

\section{Reagents}

Unless otherwise stated, all chemicals were of reagent-grade quality and were purchased from Sigma (St. Louis, MO). Methanol (HPLC grade), perchloric acid, hydrochloric acid, and sodium hydroxide were obtained from Fisher Scientific (Pittsburgh, PA). Reagents for immunohistochemistry were purchased from Vector Laboratories (Burlingdale, CA) and Dako Laboratories (Santa Barbara, CA) as specified in the procedures.

\section{Animals}

\section{Study 1 in the model of streptozotocin (STZ)-induced diabetes}

Male C57BL6 mice, body weights $23-26$ g, were treated with STZ (150 mg kg-1 i.p.). Blood samples for measurements of glucose were taken from the tail vein $\sim 48 \mathrm{~h}$ after the STZ injection and the day before animals were killed. The mice with blood glucose $\geq 13.8 \mathrm{mM}$ were considered diabetic. The experimental groups comprised control and diabetic mice treated with or without 
FP15 (5 mg kg body weight ${ }^{-1}$ day $^{-1}$, in the drinking water). One-week treatment was started after initial 8 wk without treatment. Both motor nerve conduction velocity (MNCV) and sensory nerve conduction velocity (SNCV) deficits develop in STZ-diabetic mice in $<3$ wk after induction of diabetes (28).

\section{Study 2 in NOD mouse model}

NOD female mice starting at 5 wk of age, body weights 20-23 g, had their urine glucose levels checked using Tes-Tape (Eli Lilly, Ontario, Canada) three times per week. The mice were considered diabetic following 3 days of glucosuria and with blood glucose concentration on the third day $\geq 13.8 \mathrm{mM}$. One-week treatments ( 1 or $3 \mathrm{mg} \mathrm{kg}$ body weight ${ }^{-1}$ day $^{-1}$, by gavage) were started after initial 12 wk without treatment. Diabetic NOD mice had their tail-flick response determined on day 0 . The mice were then treated with either 1 or $3 \mathrm{mg} \mathrm{kg}^{-1} \mathrm{~d}^{-1} \mathrm{FP} 15$ by gavage for 7 days. Further tail-flick analysis was carried out on days 3 and 7 after commencing the treatment. Blood glucose levels were also monitored over the experimental period.

\section{Anesthesia}

We have previously reported $(29,30)$ that several anesthetics distort the profile of peripheral nerve metabolites, whereas a sedation by a short ( 15-20 s) exposure to carbon dioxide with immediate cervical dislocation preserves high-energy phosphate levels in the range of those obtained after decapitation without any narcosis. For this reason, two different sets of animals were used for functional and metabolic studies in the STZ-diabetic model. For functional studies that included measurements of MNCV and SNCV, the mice were anesthetized by the mixture of ketamine and xylazine $\left(75 \mathrm{mg} \mathrm{kg}\right.$ body weight ${ }^{-1}$ and $5 \mathrm{mg} / \mathrm{kg}$ body weight $^{-1}$, respectively, both i.p.). The onset (before induction of diabetes) MNCV and SNCV measurements were followed by the 8-wk time point (beginning of interventions) and final (9-wk time point) measurements. In all measurements, body temperature was monitored by a rectal probe and maintained at $37^{\circ} \mathrm{C}$ with a warming pad. Hind-limb skin temperature was also monitored by a thermistor and maintained between 36 and $38^{\circ} \mathrm{C}$ by radiant heat. For metabolic studies, the animals were sedated by $\mathrm{CO}_{2}$ in a specially designed chamber (29) and immediately killed by cervical dislocation. The left nerves were rapidly dissected, blotted with fine filter paper to remove any accompanying blood, and frozen in liquid nitrogen for subsequent measurements of phosphocreatine $(\mathrm{PCr})$ and creatine $(\mathrm{Cr})$. The right nerves were either frozen in liquid nitrogen for subsequent measurements of the sorbitol pathway intermediates or fixed in formalin and later used for immunohistochemistry.

\section{Functional studies}

\section{Sciatic MNCV}

The left sciatic nerve was stimulated proximally at the sciatic notch and distally at the ankle via bipolar electrodes with supramaximal stimuli (8V) at $20 \mathrm{~Hz}$. The latencies of the compound muscle action potentials were recorded via bipolar electrodes from the first interosseous muscle of the hindpaw and measured from the stimulus artifact to the onset of the negative M-wave deflection. MNCV was calculated by subtracting the distal latency from the proximal latency and the result divided into the distance between the stimulating and recording electrode. 


\section{Digital SNCV}

Hind-limb SNCV was recorded in the digital nerve to the second toe by stimulating with a square-wave pulse of 0.05 msec duration using the smallest intensity current, which resulted in a maximal amplitude response. The sensory nerve action potential was recorded behind the median malleolus. Sixteen responses were averaged to obtain the position of the negative peak. The maximal SNCV was calculated by measuring the latency to the onset/peak of the initial negative deflection and the distance between stimulating and recording electrodes.

\section{Tail-flick response latencies}

Tail-flick latencies were determined using the IITC model 33 tail-flick algesia meter (IITC Life Science, Woodland Hills, CA) set at $40 \%$ intensity and with a cut off at 8 s. Two readings were taken per animal at a 15-min interval, and the average of the two readings was calculated.

\section{Metabolic studies}

The steady-state concentrations of PCr and Cr were assayed in perchloric acid extracts of the left sciatic nerve spectrofluorometrically by enzymatic procedures $(29,30)$. The concentrations of glucose, sorbitol, and fructose have been assayed as we have previously described (29, 30).

\section{Immunohistochemical studies}

All immunohistochemical samples were coded and examined by a single investigator in a blinded fashion. Microphotographs were taken with a Zeiss Axiolab microscope equipped with a Fuji HC-300C digital camera.

\section{Nitrotyrosine (NT) immunoreactivity}

Sciatic nerve tyrosine nitration was measured as we have described previously (31). Sciatic nerves were fixed in 4\% paraformaldehyde in PBS, and 5- $\mu \mathrm{m}$ sections were prepared from paraffin-embedded tissues. Endogenous peroxidase was quenched with $0.3 \% \mathrm{H}_{2} \mathrm{O}_{2}$ in $60 \%$ methanol for 15 min. The sections were incubated overnight with 1:1000-1:2000 dilution of primary anti-nitrotyrosine antibody (Upstate Biotechnology, Lake Placid, NY). In control measurements, tissues were incubated with the primary antibody in the presence of $10 \mathrm{mM}$ nitrotyrosine. Specific labeling was detected with a biotin-conjugated goat anti-rabbit IgG and avidin-biotin peroxidase complex, both supplied in the Vector Elite kit (Vector Laboratories). Color was developed using Ni-diaminobenzidine substrate kit (Vector Laboratories). The sections were counterstained with nuclear fast red, dehydrated, and mounted in Permount. The photomicrographs shown are representative sections $(n=5-6)$ for each experimental group.

\section{Poly(ADP-ribose) and PARP-1 immunoreactivities}

Paraffin sections $(5 \mu \mathrm{m})$ were loaded onto polysine-coated slides (Fisher, Atlanta, GA), deparaffinzed and rehydrated. Optimal staining was achived with antigen retrieval method, which was performed in $10 \mathrm{mmol} / \mathrm{l}$ citric acid for $15 \mathrm{~min}$. Endogenous peroxidase was quenched with $0.3 \% \mathrm{H}_{2} \mathrm{O}_{2}$ in $60 \%$ methanol for $15 \mathrm{~min}$. Sections were blocked with $2 \%$ normal goat serum at room temperature for $1-2 \mathrm{~h}$ and were incubated overnight with 1:250-1:500 dilution of 
primary anti-poly(ADP)-ribose antibody (generous gift from Tulip Biolabs, West Point, PA) or 1:500 dilution of anti-PARP-1 antibody (Alexis Biochemicals, San Diego, CA). Specific labeling was detected with a biotin-conjugated goat anti-chicken IgG for PAR and biotin-conjugated antirabbit IgG for PARP and avidin-biotin peroxidase complex (Vector Laboratories). The enzymatic reaction product was enhanced with nickel cobalt to give a black precipitate, and the sections were counterstained with nuclear fast red, dehydrated, and mounted in Permount. Positive controls included formalin-fixed, paraffin-embedded tissues from LPS-treated rats. Negative controls included elimination of the primary antibody.

\section{Statistical analysis}

The results are expressed as mean \pm SE. Data were subjected to equality of variance $F$ test, and then to log transformation, if necessary, before one-way ANOVA. Where overall significance $(P<0.05)$ was attained, individual between-group comparisons were made using the StudentNewman-Keuls multiple range test. Significance was defined at $P \leq 0.05$. When between-group variance differences could not be normalized by log transformation (datasets for body weights, plasma glucose, and some metabolic parameters), the data were analyzed by the nonparametric Kruskal-Wallis one-way ANOVA, followed by the Bonferroni/Dunn test for multiple comparisons.

\section{RESULTS}

The final body weights were comparably lower in untreated and FP15-treated STZ-diabetic mice than in the corresponding nondiabetic groups (Table 1). The final blood glucose concentrations were similarly elevated in untreated and FP15-treated STZ-diabetic mice compared with the nondiabetic control mice.

No statistically significant differences in initial and final body weights were found among nondiabetic and diabetic NOD mice treated with or without FP15 (Table 2). The final blood glucose concentrations were similarly elevated in untreated and FP15-treated NOD mice compared with the nondiabetic control mice.

The onset MNCV and SNCV (before induction of STZ-diabetes) for all experimental groups in study 1, as well as MNCV and SNCV at the beginning of interventions, that is, the 8-wk time point, are given in Table 3. Both MNCV and SNCV are reduced in diabetic mice with 8-wk duration of diabetes. They remained reduced after 9 wk of diabetes in the untreated group, whereas a 1-wk FP15 treatment resulted in a complete correction of MNCV deficit and essential correction of sensory nerve conduction slowing (Fig. 1A). FP15 treatment did not affect either MNCV or SNCV in nondiabetic mice.

The tail-flick latency was increased in diabetic NOD mice compared with the nondiabetic group $(P<0.001$, Fig. $1 B)$, and this decreased responsiveness to acute pain was dose-dependently corrected by FP15 treatment. A reduction of tail-flick latency was observed after 7 days of the low-dose FP15 administration; however, the tail-flick latency still remained greater than in nondiabetic mice. A 3-day high-dose FP15 treatment caused a reduction of the tail-flick latency. Diabetes-associated thermal hypoalgesia was completely corrected by a 7-day FP15 treatment: 
no difference was found between the tail-flick latencies in nondiabetic NOD mice and diabetic NOD mice treated with $3 \mathrm{mg} \mathrm{kg}^{-1}$ day $^{-1}$ FP15.

Sciatic nerve PCr concentration and PCr/Cr ratio were reduced in STZ-diabetic mice compared with the corresponding controls (Fig. 1C). Both indices of peripheral nerve energy state were corrected in STZ-diabetic mice treated with FP15. FP15 administration did not affect either PCr concentration or $\mathrm{PCr} / \mathrm{Cr}$ ratio in control mice.

Sciatic nerve glucose, sorbitol, and fructose concentrations were increased in STZ-diabetic mice compared with controls (Fig. 1D). FP15 treatment did not affect nerve glucose, sorbitol, or fructose concentrations in either control or diabetic mice.

Increased sciatic nerve NT immunoreactivity was found in STZ-diabetic mice (Fig. $2 A)$. In contrast, NT staining in the sciatic nerve was barely detectable in STZ-diabetic mice treated with FP15. The NT staining intensity in FP15-treated diabetic mice was comparable to nondiabetic groups.

Increased sciatic nerve poly(ADP-ribose) immunoreactivity was found in STZ-diabetic mice (Fig. 2B). One-wk FP15 treatment markedly reduced nerve poly(ADP-ribose) immunoreactivity. Note, that poly(ADP-ribose)-positive nuclei were scarce but still present in sciatic nerves of the FP15-treated diabetic group.

Sciatic nerve PARP-1 immunoreactivity was similar among nondiabetic and STZ-diabetic mice treated with or without FP15 (Fig. 2C).

\section{DISCUSSION}

Numerous studies in animal models $(10-12,14,15,30)$ and, recently, several clinical investigations $(32,33)$ demonstrate that oxidative stress is one of the leading factors in the pathogenesis of peripheral diabetic neuropathy. Diabetes-induced oxidative stress has been welldocumented in the circulation (systemic oxidative stress) (34) and major elements of the peripheral nervous system $(4,11,12,35)$ and has been implicated in nerve conduction deficits (11, 12, 14, 15, 30), changes in signal transduction and metabolism (29, 36), impaired neurotrophic support (37), neurovascular dysfunction (11, 12, 14, 15, 30), and morphological abnormalities (38) characteristic for diabetic neuropathy. Whereas the role for superoxide and hydroxyl radicals in diabetes-induced neurovascular dysfunction and nerve conduction deficits has specifically been addressed in several recent studies (12, 15, 39), the role for the potent cytotoxic oxidant peroxynitrite, a product of superoxide anion and nitric oxide, in diabetic neuropathy has not yet been elucidated. Studies in nondiabetic models revealed that peroxynitrite triggers lipid peroxidation, DNA strand breakage and base modification, and protein nitration and nitrosylation, and causes cell necrosis and apoptosis (21). The product of tyrosine nitration, nitrotyrosine, a relatively specific marker of peroxynitrite formation, has been detected in both experimental $(11,12,16)$ and clinical (17) diabetic neuropathy. However, a direct demonstration of the pathogenetic role of peroxynitrite required pharmacological tools that would have an ability to effectively neutralize peroxynitrite in vivo.

Here we describe the effect of the potent and in vivo active peroxynitrite decomposition catalyst on indices of diabetic neuropathy in two models of type 1 (insulin-dependent) diabetes: STZ- 
diabetic mice and diabetic NOD mice. This catalyst has previously been used in several in vivo studies and has demonstrated effectiveness in various models of inflammation and reperfusion injury $(40,41)$. None of these studies, including ours, assessed its effect on superoxide dismutation in animal tissues, whereas the presence of such activity for this class of compounds has been reported in vitro (24). However, the fact that orally administered FP15 is effective in correcting a number of pathological conditions associated with oxidative stress, including early diabetic neuropathy, in much lower doses than typical superoxide dismutase mimetics (compare refs 18 and 42; refs 41, 43, and 44; and our study and ref 12) strongly suggests the major contribution of peroxynitrite to oxidative/nitrosative stress-induced cytotoxic effects in diabetic peripheral nerve.

Our findings provide the first evidence of the major role for reactive nitrogen species in motor and sensory nerve conduction deficits, nerve energy failure, and thermal hypoalgesia characteristic for peripheral diabetic neuropathy. Diabetes-induced nerve dysfunction, energy deficiency, and reduced pain sensitivity were all reversed by the peroxynitrite decomposition catalyst FP15. Note that these effects of FP15 were not due to correction or alleviation of hyperglycemia, as the start of the treatment was scheduled to a time point at which $\beta$-cell destruction was complete and stable hyperglycemia ensured. The introduction of this treatment protocol was necessary, as peroxynitrite also plays a role in the process of islet cell destruction associated with type I (insulin-dependent) diabetes (18). Also note that FP15 was effective on the aforementioned physiological and metabolic abnormalities at the low doses ranging from 1 to 5 $\mathrm{mg} \mathrm{kg}^{-1} \mathrm{~d}^{-1}$, per os. The potency of FP15 in correcting neuropathic changes is comparable to that of the AR inhibitor fidarestat known to be highly effective on functional, metabolic, and morphological changes in experimental models of type 1 diabetes $(5,45)$. FP15 appeared far more potent in counteracting neuropathic changes than are conventional antioxidants butylated hydroxytoluene (46), vitamin E (47), and probucol $(47,48)$, and $>20$ times more potent than the "universal" antioxidant $\alpha$-lipoic acid (11,30,49-51), a compound known to possess free radical scavenging and metal chelating properties as well as an ability to regenerate levels of other antioxidants such as reduced glutathione, ascorbate, taurine, glutathione peroxidase, and catalase (52, 53). Despite normalization of nerve blood flow, $\alpha$-lipoic acid failed to correct peripheral nerve energy state (consistent with the absence of prevention of motor nerve conduction deficit in several studies [30, 49, 51], including ours, ref 30]), whereas FP15 corrected both nerve energy and MNCV deficits. The latter is in line with suppression of diabetes-associated PARP activation in peripheral nerve of FP15-treated mice (Fig. $2 B$, see discussion below). PARP activation depletes peripheral nerve PCr levels (28), because resynthesis of one molecule of $\mathrm{NAD}^{+}$, cleaved by PARP to nicotinamide plus ADP-ribose and playing a critical role in cell function and metabolism, requires four molecules of ATP (20), a high-energy phosphate supplied by its storage form, PCr, via creatine phosphokinase-catalyzed reaction. Furthermore, FP15 dose-dependently reversed thermal hypoalgesia in NOD diabetic mice, a model with clearly manifest early diabetic autonomic neuropathy (54) that has not previously been used for evaluation of peripheral neuropathy. As one can see from this study, an advantage of this model is early development of hypoalgesia, that is, sensory loss, known to develop in patients with diabetes mellitus and be responsible for increased foot ulceration and amputation (55). The effect on tail-flick latency was seen with such low doses as $1 \mathrm{mg} \mathrm{kg}^{-1} \mathrm{day}^{-1}$ after 1 -wk administration, and $3 \mathrm{mg} \mathrm{kg}$ day $^{-1}$ after 3-wk administration. A far better efficacy of FP15 compared with conventional antioxidants (known to react only slowly with peroxynitrite [56]) against 
neuropathic changes of DN provides indirect evidence of importance of reactive nitrogen species in diabetes-associated nerve functional deficits.

Our immunohistochemical studies indicate that FP15 effectively penetrates into a peripheral nerve. The diabetes-associated increase in NT immunoreactivity was essentially corrected by FP15 treatment. The peroxynitrite decomposition catalyst did not affect the abundance of PARP1 (a constitutively expressed protein, with relatively little transcriptional regulation [20]) but did reduce poly(ADP-ribose) immunoreactivity (the product of PARP catalytic activation) in the diabetic nerve. This is consistent with other studies indicating that antioxidants, superoxide dismutase mimetics, and other agents counteracting oxidative-nitrosative stress do not affect the abundance of PARP-1 protein, but do reduce PARP catalytic activation, presumably by preventing oxidative damage to DNA (20). We have recently reported that PARP activation is a fundamental mechanism of peripheral diabetic neuropathy $(28,57)$ and that neuropathic changes in short-term type 1 diabetes do not develop in PARP-deficient mice (28). The present study provides evidence of the key role of peroxynitrite in PARP activation in the diabetic peripheral nerve. Note that FP15-treated STZ-diabetic mice still had scarce poly(ADP-ribose)-positive nuclei in their sciatic nerves. This finding may be explained by alternative routes of DNA strand breakage in diabetes, triggered by species others than peroxynitrite, for example, hydrogen peroxide, hydroxyl radical, and/or nitroxyl anion (20).

Whereas the relationship between oxidative stress and other mechanisms in the pathogenesis of diabetic neuropathy requires further studies, it is clear from our findings that peroxynitrite does not cause AR activation and sorbitol pathway intermediate accumulation in the diabetic peripheral nerve. Sciatic nerve concentrations of glucose, sorbitol, and fructose were similarly elevated in untreated and FP15-treated diabetic mice. Furthermore, we have recently obtained evidence that increased AR activity is responsible for nitrosative stress and PARP activation in early experimental diabetic neuropathy (58). The latter finding is not surprising considering that 1) increased AR activity plays a key role in superoxide formation (59-61) and other manifestations of oxidative stress $(4,10)$ and that 2$)$ the neural compartment of peripheral nerve of, at least, short-term diabetic animals lacks two other important mechanisms contributing to oxidative stress in tissue sites for diabetic complications, that is, nonenzymatic glycation and activation of protein kinase C (62). The contribution of glycation and PKC activation known to take place in vasa nervorum in diabetic conditions to ROS and reactive nitrogen species generation in the whole peripheral nerve is minor.

The consequences of diabetes-associated nitrosative stress probably extend (via PARP) to alterations in transcription factors and complex dysregulation of gene expression (20). The candidate genes are the most likely to include interleukin-1 $\beta,-6$, and -8; inducible nitric oxide synthase; cyclooxygenase-2; and endothelin-1 (20, 63, 64). Another consequence of nitrosative stress could be activation of mitogen-activated protein kinases (MAPKs, [65]) known to play the most important role in the pathogenesis of peripheral diabetic neuropathy $(5,36)$. Several studies suggest that peroxynitrite regulates a release of glutamate and aspartate, two excitatory amino acids involved in control of algesia $(66,67)$. The effect of FP15 of thermal algesia may be mediated via several mechanisms, including alterations in glutamate and aspartate concentrations, neurotrophic factors, and PARP-mediated changes in calcium signaling in dorsal root ganglion neurons. 
In conclusion, our findings provide evidence for the major role for nitrosative stress, that is, peroxynitrite-induced injury in the pathogenesis of peripheral diabetic neuropathy. The results complement several recent studies revealing the importance of reactive nitrogen species in islet cell destruction (18) and diabetic cardiovascular complications (18) in type 1 diabetes. Furthermore, peroxynitrite-induced damage is likely to be implicated in increased vascular permeability, disruption of blood-retinal barrier, leukocyte adhesion to endothelial cells, and premature apoptosis characteristic for diabetic retinopathy, and glomerulosclerosis, tubulointerstitial fibrosis, and progressive decline in glomerular filtration rate characteristic for diabetic nephropathy $(68,69)$. The delineation of the role of peroxynitrite in these processes requires additional studies. The results of the present study provide rationale for the additional testing and development of agents with the ability to counteract peroxynitrite formation and/or to enhance peroxynitrite decomposition for prevention and treatment of neuropathy and other diabetic complications.

\section{ACKNOWLEDGMENTS}

The study was supported by an American Diabetes Association research grant and National Institutes of Health grant DK59809-01 (both to Irina G.Obrosova) and National Institutes of Health grant HL/DK 71215-01 (to Csaba Szabó).

\section{REFERENCES}

1. Boulton, A. J., Malik, R. A., Arezzo, J. C., and Sosenko, J. M. (2004) Diabetic somatic neuropathies. Diab. Care 27, 1458-1486

2. Writing Team for the Diabetes Control and Complications Trial/Epidemiology of Diabetes Interventions and Complications Research Group (2002) Effect of intensive therapy on the microvascular complications of type 1 diabetes mellitus. JAMA 287, 2563-2569

3. Hotta, N., Toyota, T., Matsuoka, K., Shigeta, Y., Kikkawa, R., Kaneko, T., Takahashi,A., Sugimura, K., Koike, Y., Ishii, J., Sakamoto, N., and SNK-860 Diabetic Neuropathy Study Group (2001) Clinical efficacy of fidarestat, a novel aldose reductase inhibitor, for diabetic peripheral neuropathy: a 52-wk multicenter placebo-controlled double-blind parallel group study. Diab. Care 24, 1776-1782

4. Obrosova, I. G., Van Huysen, C., Fathallah, L., Cao, X. C., Greene, D. A., and Stevens, M. J. (2002) An aldose reductase inhibitor reverses early diabetes-induced changes in peripheral nerve function, metabolism, and antioxidative defense. FASEB J. 16, 123-125

5. Price, S. A., Agthong, S., Middlemas, A. B., and Tomlinson, D. R. (2004) Mitogen-activated protein kinase p38 mediates reduced nerve conduction velocity in experimental diabetic neuropathy: interactions with aldose reductase. Diabetes 53, 1851-1856

6. Thornalley, P. J. (2002) Glycation in diabetic neuropathy: characteristics, consequences, causes, and therapeutic options. Int. Rev. Neurobiol. 50, 37-57

7. Nakamura, J., Kato, K., Hamada, Y., Nakayama, M., Chaya, S., Nakashima, E., Naruse, K., Kasuya, Y., Mizubayashi, R., Miwa, K., et al. (1999) A protein kinase C-beta-selective 
inhibitor ameliorates neural dysfunction in streptozotocin-induced diabetic rats. Diabetes 48, 2090-2095

8. Mizisin, A. P., Steinhardt, R. C., O'Brien, J. S., and Calcutt, N. A. (2001) TX14(A), a prosaposin-derived peptide, reverses established nerve disorders in streptozotocin-diabetic rats and prevents them in galactose-fed rats. J. Neuropathol. Exp. Neurol. 60, 953-960

9. Sayers, N. M., Beswick, L. J., Middlemas, A., Calcutt, N. A., Mizisin, A. P., Tomlinson, D. R., and Fernyhough, P. (2003) Neurotrophin-3 prevents the proximal accumulation of neurofilament proteins in sensory neurons of streptozocin-induced diabetic rats. Diabetes 52, 2372-2380

10. Obrosova, I. G. (2002) How does glucose generate oxidative stress in peripheral nerve? Int. Rev. Neurobiol. 50, 3-35

11. Coppey, L. J., Gellett, J. S., Davidson, E. P., Dunlap, J. A., Lund, D. D., and Yorek, M. A. (2001) Effect of antioxidant treatment of streptozotocin-induced diabetic rats on endoneurial blood flow, motor nerve conduction velocity, and vascular reactivity of epineurial arterioles of the sciatic nerve. Diabetes 50, 1927-1937

12. Coppey, L. J., Gellett, J. S., Davidson, E. P., Dunlap, J. A., Lund, D. D., Salvemini, D., and Yorek, M. A. (2001) Effect of M40403 treatment of diabetic rats on endoneurial blood flow, motor nerve conduction velocity and vascular function of epineurial arterioles of the sciatic nerve. Br. J. Pharmacol. 134, 21-29

13. Brownlee, M. (2001) Biochemistry and molecular cell biology of diabetic complications. Nature 414, 813-820

14. Cotter, M. A., and Cameron, N. E. (2003) Effect of the NAD(P)H oxidase inhibitor, apocynin, on peripheral nerve perfusion and function in diabetic rats. Life Sci. 73, 18131824

15. Cameron, N., Tuck, Z., McCabe, L., and Cotter, M. A. (2001) Effect of the hydroxyl radical scavenger, dimethylthiourea, on peripheral nerve tissue perfusion, conduction velocity and nociception in experimental diabetes. Diabetologia 44, 1161-1169

16. Cheng, C., and Zochodne, D. W. (2003) Sensory neurons with activated caspase-3 survive long-term experimental diabetes. Diabetes 52, 2363-2371

17. Hoeldtke, R. D., Bryner, K. D., McNeill, D. R., Hobbs, G. R., Riggs, J. E., Warehime, S. S., Christie, I., Ganser, G., and Van Dyke, K. (2002) Nitrosative stress, uric acid, and peripheral nerve function in early type 1 diabetes. Diabetes 51, 2817-2825

18. Szabo, C., Mabley, J. G., Moeller, S. M., Shimanovich, R., Pacher, P., Virag, L., Soriano, F. G., Van Duzer, J. H., Williams, W., Salzman, A. L., et al. (2002) Part I: pathogenetic role of peroxynitrite in the development of diabetes and diabetic vascular complications: studies with FP15, a novel potent peroxynitrite decomposition catalyst. Mol. Med. 8, 571-580 
19. Garcia Soriano, F., Virag, L., Jagtap, P., Szabo, E., Mabley, J. G., Liaudet, L., Marton, A., Hoyt, D. G., Murthy, K. G., Salzman, A. L., et al. (2001) Diabetic endothelial dysfunction: the role of poly(ADP-ribose) polymerase activation. Nat. Med. 7, 108-113

20. Virag, L., and Szabo, C. (2002) The therapeutic potential of poly(ADP-ribose) polymerase inhibitors. Pharmacol. Rev. 54, 375-429

21. Virag, L., Szabo, E., Gergely, P., and Szabo, C. (2003) Peroxynitrite-induced cytotoxicity: mechanism and opportunities for intervention. Toxicol. Lett. 140-141, 113-124

22. Groves, J. T. (2004) Models and mechanisms of cytochrome P-450 action. In Cytochrome P450: Structure, Mechanism, and Biochemistry, 3rd ed., pp 1-44 (Ortiz de Montellano, P. R., ed) Kluwer Academic/Plenum Publishers, New York

23. Groves, J. T., and Marla, S. (1995) Peroxynitrite-Induced DNA StrandScission Mediated by a Manganese Porphyrin. J. Am. Chem. Soc. 117, 9578-9579

24. Lee, J., Hunt, J. A., and Groves, J. T. (1998) Mechanisms of iron porphyrin reactions with peroxynitrite. J. Am. Chem. Soc. 120, 7493-7501

25. Shimanovich, R., and Groves, J. T. (2001) Mechanisms of peroxynitrite decomposition catalyzed by FeTMPS, a bioactive sulfonated iron porphyrin. Arch. Biochem. Biophys. 387, 307-317

26. Groves, J. T. (1999) Peroxynitrite: reactive, invasive and enigmatic. Curr. Opinion Chem. Biol. 3, 226-235

27. Marla, S. S., Lee, J., and Groves, J. T. (1997) Peroxynitrite rapidly permeates phospholipid membranes. Proc. Natl. Acad. Sci. USA 94, 14243-14248

28. Obrosova, I. G., Li, F., Abatan, O. I., Forsell, M. A., Komjati, K., Pacher, P., Szabo, C., and Stevens, M. J. (2004) Role of poly(ADP-ribose) polymerase activation in diabetic neuropathy. Diabetes 53, 711-720

29. Obrosova, I. G., Fathallah, L., Lang, H. J., and Greene, D. A. (1999) Evaluation of a sorbitol dehydrogenase inhibitor on diabetic peripheral nerve metabolism: a prevention study. Diabetologia 42, 1187-1194

30. Stevens, M. J., Obrosova, I., Cao, X., Van Huysen, C., and Greene, D. A. (2000) Effects of DL-alpha-lipoic acid on peripheral nerve conduction, blood flow, energy metabolism, and oxidative stress in experimental diabetic neuropathy. Diabetes 49, 1006-1015

31. Zingarelli, B., Cuzzocrea, S., Zsengeller, Z., Salzman, A. L., and Szabo, C. (1997) Protection against myocardial ischemia and reperfusion injury by 3-aminobenz-amide, an inhibitor of poly (ADP-ribose) synthetase. Cardiovasc. Res. 36, 205-215

32. Ametov, A. S., Barinov, A., Dyck, P. J., Hermann, R., Kozlova, N., Litchy, W. J., Low, P. A., Nehrdich, D., Novosadova, M., O'Brien, P. C., et al., and SYDNEY Trial Study Group. 
(2003) The sensory symptoms of diabetic polyneuropathy are improved with alpha-lipoic acid: the SYDNEY trial. Diab. Care 26, 770-776

33. Ziegler, D., Nowak, H., Kempler, P., Vargha, P., and Low, P. A. (2004) Treatment of symptomatic diabetic polyneuropathy with the antioxidant alpha-lipoic acid: a metaanalysis. Diab. Med. 21, 114-121

34. Van Dam, P. S., Bravenboe, B., van Asbeck, B. S., van Oirschot, J. F., Marx, J. J., and Gispen, W. H. (1996) Effects of insulin treatment on endoneurial and systemic oxidative stress in relation to nerve conduction in streptozotocin-diabetic rats. Eur. J. Clin. Invest. 26, 1143-1149

35. Schmeichel, A. M., Schmelzer, J. D., and Low, P. A. (2003) Oxidative injury and apoptosis of dorsal root ganglion neurons in chronic experimental diabetic neuropathy. Diabetes 52, 165-171

36. Purves, T., Middlemas, A., Agthong, S., Jude, E. B., Boulton, A. J., Fernyhough, P., and Tomlinson, D. R. (2001) A role for mitogen-activated protein kinases in the etiology of diabetic neuropathy. FASEB J. 15, 2508-2514

37. Hounsom, L., Corder, R., Patel, J., and Tomlinson, D. R. (2001) Oxidative stress participates in the breakdown of neuronal phenotype in experimental diabetic neuropathy. Diabetologia 44, 424-428

38. Sagara, M., Satoh, J., Wada, R., Yagihashi, S., Takahashi, K., Fukuzawa, M., Muto, G., Muto, Y., and Toyota, T. (1996) Inhibition of development of peripheral neuropathy in streptozotocin-induced diabetic rats with N-acetylcysteine. Diabetologia 39, 263-269

39. Coppey, L. J., Gellett, J. S., Davidson, E. P., and Yorek, M. A. (2003) Preventing superoxide formation in epineurial arterioles of the sciatic nerve from diabetic rats restores endothelium-dependent vasodilation. Free Radic. Res. 37, 33-40

40. Mabley, J. G., Liaudet, L., Pacher, P., Southan, G. J., Salzman, A. L., Groves, J. T., and Szabo, C. (2002) Part II: beneficial effects of the peroxynitrite decomposition catalyst FP15 in murine models of arthritis and colitis. Mol. Med. 8, 581-590

41. Pacher, P., Liaudet, L., Bai, P., Mabley, J. G., Kaminski, P. M., Virag, L., Deb, A., Szabo, E., Ungvari, Z., Wolin, M. S., et al. (2003) Potent metalloporphyrin peroxynitrite decomposition catalyst protects against the development of doxorubicin-induced cardiac dysfunction. Circulation 107, 896-904

42. Nassar T, Kadery B, Lotan C, Da'as N, Kleinman Y, Haj-Yehia A. (2002) Effects of the superoxide dismutase-mimetic compound tempol on endothelial dysfunction in streptozotocin-induced diabetic rats. Eur. J. Pharmacol. 436, 111-118

43. Cuzzocrea, S., McDonald, M. C., Mota-Filipe, H., Mazzon, E., Costantino, G., Britti, D., Mazzullo, G., Caputi, A. P., and Thiemermann, C. (2000) Beneficial effects of tempol, a 
membrane-permeable radical scavenger, in a rodent model of collagen-induced arthritis. Arthritis Rheum. 43, 320-328

44. Karmeli, F., Eliakim, R., Okon, E., Samuni, A., and Rachmilewitz, D. (1995) A stable nitroxide radical effectively decreases mucosal damage in experimental colitis. Gut 37, 386393

45. Kato, N., Mizuno, K., Makino, M., Suzuki, T., and Yagihashi, S. (2000) Effects of 15month aldose reductase inhibition with fidarestat on the experimental diabetic neuropathy in rats. Diabetes Res. Clin. Pract. 50, 77-85

46. Love, A., Cotter, M. A., and Cameron, N. E. (1996) Nerve function and regeneration in diabetic and galactosaemic rats: antioxidant and metal chelator effects. Eur. J. Pharmacol. 314, 33-39

47. Karasu, C., Dewhurst, M., Stevens, E. J., and Tomlinson, D. R. (1995) Effects of antioxidant treatment on sciatic nerve dysfunction in streptozotocin-diabetic rats; comparison with essential fatty acids. Diabetologia 38, 129-134

48. Cameron, N. E., Cotter, M. A., Archibald, V., Dines, K. C., and Maxfield, E. K. (1994) Anti-oxidant and pro-oxidant effects on nerve conduction velocity, endoneurial blood flow and oxygen tension in nondiabetic and streptozotocin-diabetic rats. Diabetologia 37, 449459

49. Nagamatsu, M., Nickander, K. K., Schmelzer, J. D., Raya, A., Wittrock, D. A., Tritschler, H., and Low, P. A. (1995) Lipoic acid improves nerve blood flow, reduces oxidative stress, and improves distal nerve conduction in experimental diabetic neuropathy. Diab. Care 18, $1160-1167$

50. Cameron, N. E., Cotter, M. A., Horrobin, D. H., and Tritschler, H. J. (1998) Effects of alpha-lipoic acid on neurovascular function in diabetic rats: interaction with essential fatty acids. Diabetologia 41, 390-399

51. Hounsom, L., Horrobin, D. F., Tritschler, H., Corder, R., and Tomlinson, D. R. (1998) A lipoic acid-gamma linolenic acid conjugate is effective against multiple indices of experimental diabetic neuropathy. Diabetologia 41, 839-843

52. Maitra, I., Serbinova, E., Trischler, H., and Packer, L. (1995) Alpha-lipoic acid prevents buthionine sulfoximine-induced cataract formation in newborn rats. Free Radic. Biol. Med. 18, 823-829

53. Packer, L., Kraemer, K., and Rimbach, G. (2001) Molecular aspects of lipoic acid in the prevention of diabetes complications. Nutrition 17, 888-895

54. Schmidt, R. E., Dorsey, D. A., Beaudet, L. N., Frederick, K. E., Parvin, C. A., Plurad, S. B., and Levisetti, M. G. (2003) Non-obese diabetic mice rapidly develop dramatic sympathetic neuritic dystrophy. Am. J. Pathol. 163, 2077-2091 
55. Boulton, A. J. (2004) The diabetic foot: from art to science. The 18th Camillo Golgi lecture. Diabetologia 47, 1343-1353

56. Lee, J., Hunt, A., and Groves, J. T. (1997) Rapid decomposition of peroxynitrite by manganese porphyrin-antioxidant redox-couples. Bioorg. Med. Chem. Lett. 7, 2913-2918

57. Li, F., Szabo, C., Pacher, P., Southan, G. J., Abatan, O. I., Charniauskaya, T., Stevens, M. J., and Obrosova, I. G. (2004) Evaluation of orally active poly(ADP-ribose) polymerase inhibitor in streptozotocin-diabetic rat model of early peripheral neuropathy. Diabetologia 47, 710-717

58. Obrosova, I. G., Szabo, C., Pacher, P., Hirooka, H., Stevens, M. J., and Yorek, M. A. (2004) Aldose reductase inhbitor fidarestat counteracts nitrosative stress and poly(ADP-ribose) polymerase activation in experimental diabetic neuropathy. Diabetes 53, Suppl 2, A213 (abstract)

59. Gupta, S., Chough, E., Daley, J., Oates, P., Tornheim, K., Ruderman, N. B., and Keaney, J. F., Jr. (2002) Hyperglycemia increases endothelial superoxide that impairs smooth muscle cell Na+-K+-ATPase activity. Am. J. Physiol. Cell Physiol. 282, C560-C566

60. Obrosova, I. G., Minchenko, A. G., Vasupuram, R., White, L., Abatan, O. I., Kumagai, A. K., Frank, R. N., and Stevens, M. J. (2003) Aldose reductase inhibitor fidarestat prevents retinal oxidative stress and vascular endothelial growth factor overexpression in streptozotocin-diabetic rats. Diabetes 52, 864-871

61. El-Remessy, A. B., Abou-Mohamed, G., Caldwell, R. W., and Caldwell, R. B. (2003) High glucose-induced tyrosine nitration in endothelial cells: role of eNOS uncoupling and aldose reductase activation. Invest. Ophthalmol. Vis. Sci. 44, 3135-3143

62. Obrosova, I. G. (2003) Update on the pathogenesis of diabetic neuropathy. Curr. Diab. Rep. 3, 439-445

63. Ha, H. C., Hester, L. D., and Snyder, S. H. (2002) Poly(ADP-ribose) polymerase-1 dependence of stress-induced transcription factors and associated gene expression in glia. Proc. Natl. Acad. Sci. USA 99, 3270-3275

64. Minchenko, A. G., Stevens, M. J., White, L., Abatan, O. I., Komjati, K., Pacher, P., Szabo, C., and Obrosova, I. G. (2003) Diabetes-induced overexpression of endothelin-1 and endothelin receptors in the rat renal cortex is mediated via poly(ADP-ribose) polymerase activation. FASEB J. 17, 1514-1516

65. Klotz, L. O., Schroeder, P., and Sies, H. (2002) Peroxynitrite signaling: receptor tyrosine kinases and activation of stress-responsive pathways. Free Radic. Biol. Med. 33, 737-743

66. Moro, M. A., Leza, J. C., Lorenzo, P., and Lizasoain, I. (1998) Peroxynitrite causes aspartate release from dissociated rat cerebellar granule neurones. Free Radic. Res. 28, 193-204 
67. Kimelberg, H. K. (2004) Increased release of excitatory amino acids by the actions of ATP and peroxynitrite on volume-regulated anion channels (VRACs) in astrocytes. Neurochem. Int. 45, 511-519

68. Ellis, E.A., Guberski, D.L., Hutson, B., and Grant, M.B. (2002) Time course of NADH oxidase, inducible nitric oxide synthase and peroxynitrite in diabetic retinopathy in the BBZ/WOR rat. Nitric oxide: biology and chemistry 6, 295-304

69. Santilli, F., Cipollone, F., Mezzetti, A., and Chiarelli, F. (2004) The role of nitric oxide in the development of diabetic angiopathy. Horm. Metab. Res. 36, 319-335

Received July 1, 2004; accepted November 4, 2004. 


\section{Table 1}

Final body weights and blood glucose concentrations in control and STZ-diabetic mice treated with or without FP15 (study 1) ${ }^{a}$

\begin{tabular}{|c|c|c|c|}
\hline & $\begin{array}{l}\text { Body weig } \\
\text { Initial }^{b} \\
\end{array}$ & Final & $\begin{array}{l}\text { Blood glucose } \\
(\mathrm{mmol} / \mathrm{l})\end{array}$ \\
\hline Control mice & $23.7 \pm 0.6$ & $26.8 \pm 0.5$ & $6.08 \pm 0.51$ \\
\hline Control mice treated with FP15 & $24.1 \pm 0.7$ & $26.9 \pm 0.6$ & $6.12 \pm 0.62$ \\
\hline Diabetic mice & $24.0 \pm 0.8$ & $24.9 \pm 0.5^{c}$ & $23.4 \pm 0.76^{c}$ \\
\hline Diabetic mice treated with FP15 & $24.3 \pm 0.7$ & $24.6 \pm 0.6^{c}$ & $24.1 \pm 0.92^{c}$ \\
\hline
\end{tabular}

${ }^{a}$ Data are means \pm SE, $n=26-30 .{ }^{b}$ Before induction of STZ diabetes. ${ }^{c}$ Significantly different from controls $(P<0.01)$. 
Table 2

Final body weights and blood glucose concentrations in nondiabetic and diabetic NOD mice (study 2$)^{a}$

\begin{tabular}{|c|c|c|c|c|}
\hline & \multicolumn{2}{|c|}{ Body weight (g) } & \multicolumn{2}{|c|}{ Blood glucose (mmol/l) } \\
\hline & Initial $^{b}$ & Final & Initial $^{b}$ & Final \\
\hline $\mathrm{ND}+\mathrm{FP} 15,3 \mathrm{mgkg}^{-1} \mathrm{~d}^{-1}, 7 \mathrm{~d}$ & $22.4 \pm 0.2$ & $23.1 \pm 0.2$ & $5.83 \pm 0.18$ & $5.62 \pm 0.02$ \\
\hline $\mathrm{D}+\mathrm{FP} 15,1 \mathrm{mg} \mathrm{kg}^{-1} \mathrm{~d}^{-1}, 7 \mathrm{~d}$ & $21.7 \pm 0.4$ & $22.3 \pm 0.4$ & $19.1 \pm 0.7$ & $19.9 \pm 1.3^{c}$ \\
\hline $\mathrm{D}+\mathrm{FP} 15,3 \mathrm{mgkg}^{-1} \mathrm{~d}^{-1}, 7 \mathrm{~d}$ & $22.0 \pm 0.25$ & $22.0 \pm 0.3$ & $19.1 \pm 1.2$ & $19.8 \pm 1.2^{c}$ \\
\hline
\end{tabular}

${ }^{a}$ Data are means $\pm \mathrm{SE}, n=5 .{ }^{\mathrm{b}}$ Before the beginning of the treatment. ${ }^{c}$ Significantly different from controls $(P<0.01)$ 


\section{Table 3}

The onset and 8-wk MNCV and SNCV in control and STZ-diabetic mice treated with or without FP15 ${ }^{a}$

\begin{tabular}{lllll} 
& $\begin{array}{l}\text { MNCV }(\mathbf{m} / \mathbf{s}) \\
\text { Onset }^{b}\end{array}$ & $\mathbf{8}$ wk & \multicolumn{2}{c}{$\mathbf{S N C V}(\mathbf{m} / \mathbf{s})$} \\
Onset $^{b}$ & $\mathbf{8}$ wk \\
\hline Control mice & $34.8 \pm 0.6$ & $36.8 \pm 0.5$ & $28.1 \pm 0.4$ & $29.3 \pm 0.5$ \\
Control mice treated with FP15 & $34.3 \pm 0.7$ & $36.9 \pm 0.7$ & $27.8 \pm 0.6$ & $30.0 \pm 0.6$ \\
Diabetic mice & $35.2 \pm 0.6$ & $31.9 \pm 0.6^{c}$ & $27.4 \pm 0.7$ & $24.5 \pm 0.8^{c}$ \\
Diabetic mice treated with FP15 & $34.7 \pm 0.7$ & $32.3 \pm 0.5^{c}$ & $28.2 \pm 0.8$ & $24.3 \pm 0.7^{c}$ \\
\hline
\end{tabular}

${ }^{a}$ Data are means \pm SE, $n=12-14 .{ }^{b}$ Before induction of STZ-diabetes. ${ }^{c}$ Significantly different from controls at the 8-wk timepoint $(P<0.01)$. 
Fig. 1
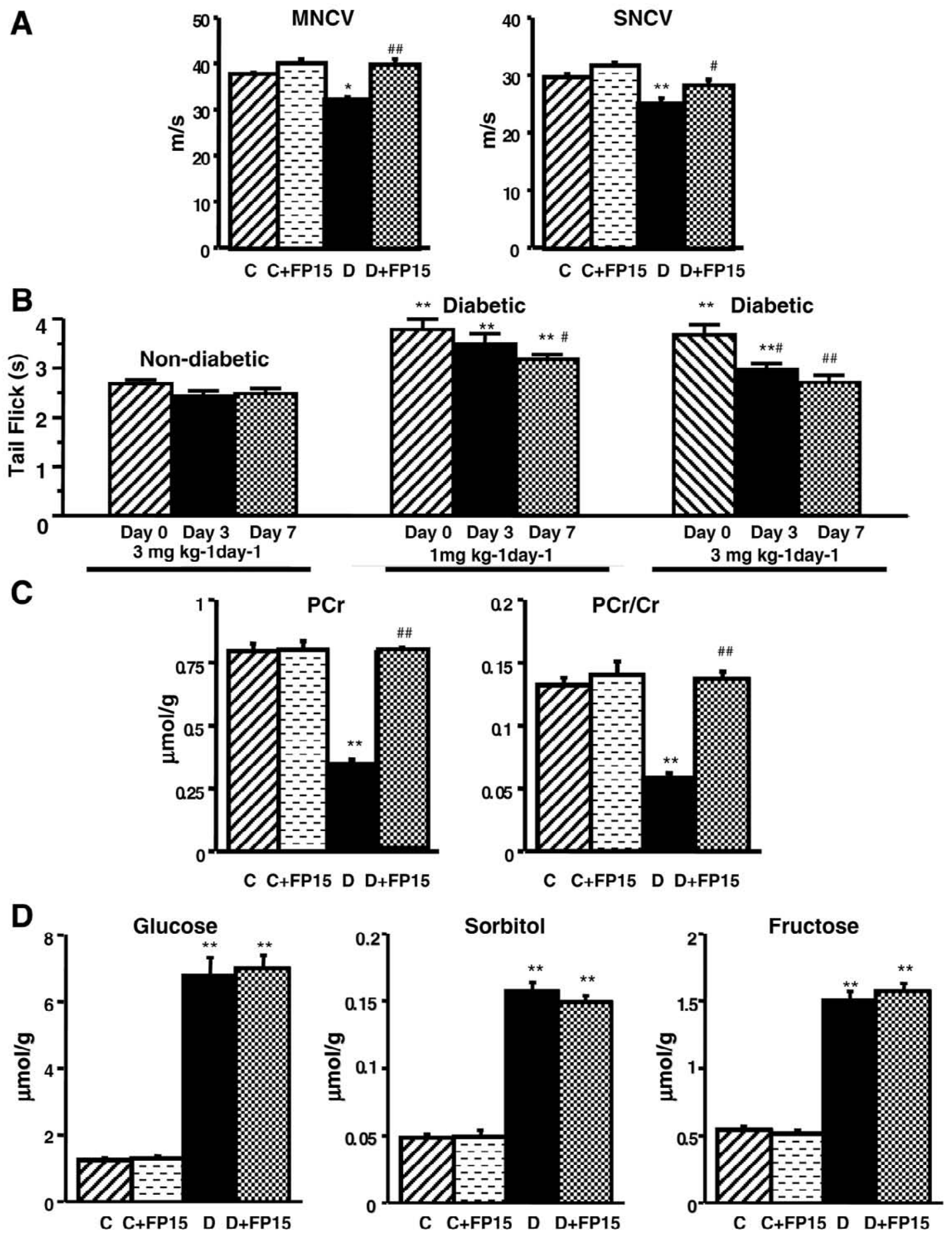

Figure 1. A) Final sciatic motor nerve conduction velocities and hind-limb digital sensory nerve conduction velocities in control and streptozotocin-diabetic mice treated with or without FP15. $n=12-14$ per group. C, control; D, diabetic. $* P<$ 0.05 and $* * P<0.01$ vs. control group; ${ }^{\#} P<0.05$ and ${ }^{\# \#} P<0.01$ vs. untreated diabetic group. $\left.\boldsymbol{B}\right)$ Tail flick latencies in nondiabetic and diabetic NOD mice treated with or without FP15. $n=5$ per group. C, control; D, diabetic. $* * P<0.01$ vs. nondiabetic group; ${ }^{\#} P<0.05$ and ${ }^{\# \#} P<0.01$ vs. corresponding values in NOD diabetic mice before treatments. $C$ ) Phosphocreatine ( $\mathrm{PCr}$ ) concentrations and phosphocreatine/creatine $(\mathrm{PCr} / \mathrm{Cr}$ ) ratios in the sciatic nerve of control and streptozotocin-diabetic mice treated with or without FP15. $n=5-6$ per group. C, control; D, diabetic. $* * P<0.01$ vs. control group; ${ }^{\#} P<0.01$ vs. untreated diabetic group. $D$ ) Glucose and sorbitol pathway intermediate concentrations in control and streptozotocin-diabetic mice treated with or without FP15. $n=6$ per group. C, control; D, diabetic. $* * P<$ 0.01 vs. control group; ${ }^{\#} P<0.01$ vs. untreated diabetic group. 
Fig. 2
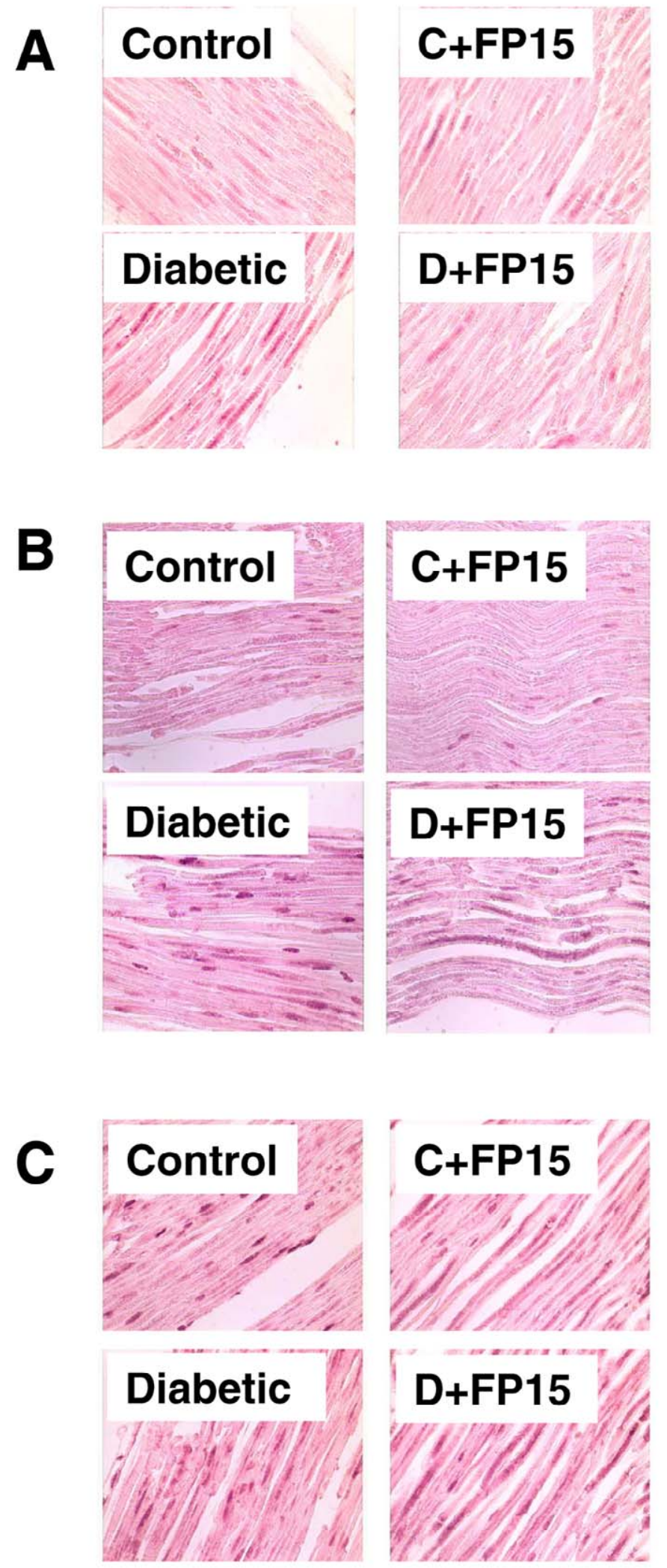

Figure 2. Representative microphotographs of immunohistochemical staining of nitrotyrosine (A), poly(ADPribose) $(B)$, and poly(ADP-ribose) polymerase-1 $(C)$ in the sciatic nerve of control and streptozotocin-diabetic mice treated with or without FP15. $n=5-6$ per group. Magnification $\times 400$. 
Fig. 3

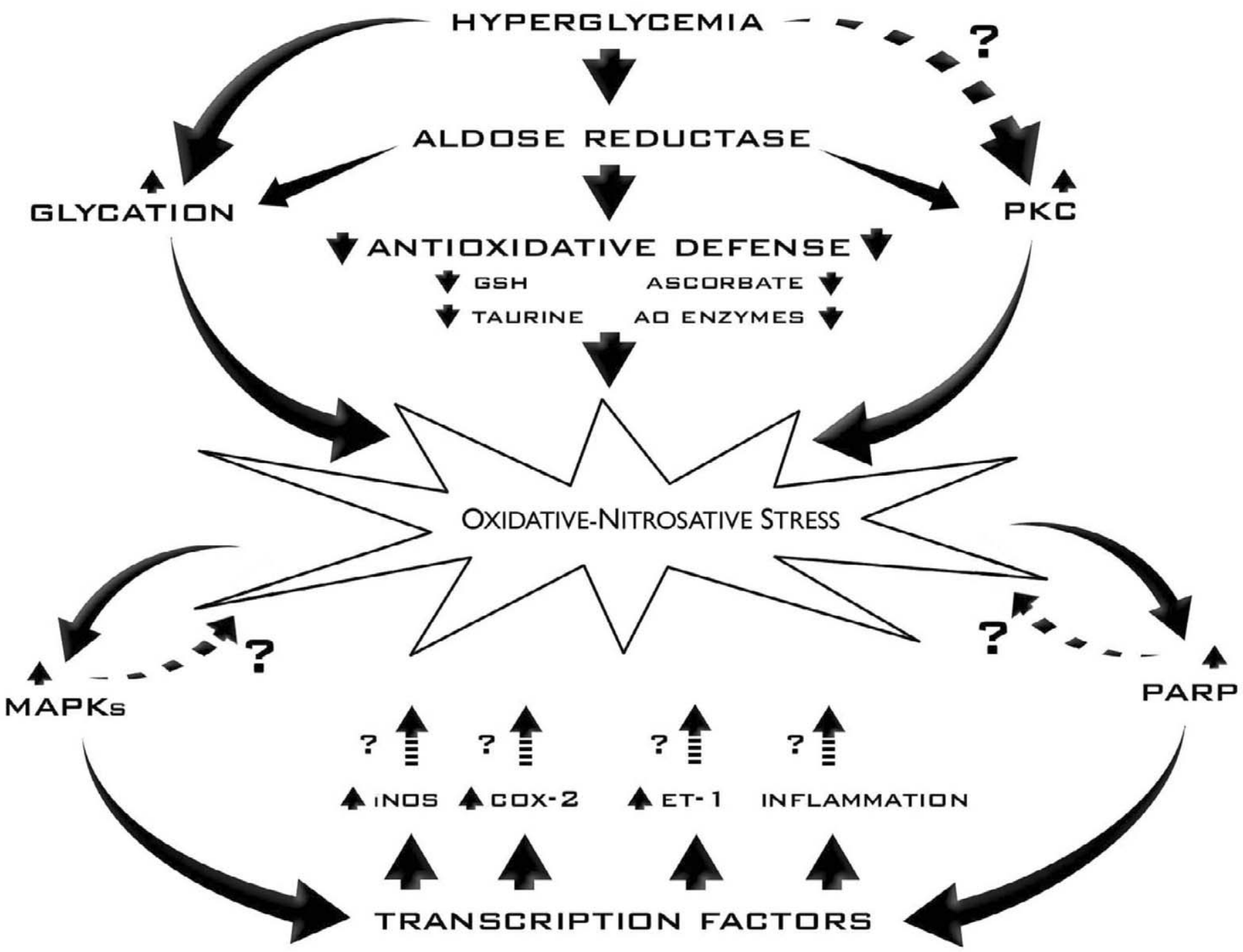

Figure 3. Interactions amongst oxidative-nitrosative stress and other mechanisms implicated in the pathogenesis of peripheral diabetic neuropathy. 